\title{
JUVENILE OSSIFYING FIBROMA: A RARE CASE REPORT
}

Ranjit S. Mandwe ${ }^{1}$, Swapna Puri², Vivek Kolhe ${ }^{3}$, Shrikant Shingne ${ }^{4}$

\section{HOW TO CITE THIS ARTICLE:}

Ranjit S. Mandwe, Swapna Puri, Vivek Kolhe, Shrikant Shingne. "Juvenile Ossifying Fibroma: A Rare Case Report”. Journal of Evolution of Medical and Dental Sciences 2014; Vol. 3, Issue 54, October 20;

Page: 12517-12522, DOI: 10.14260/jemds/2014/3658

ABSTRACT: Fibro-osseous lesions (JOF) are benign mesenchymal skeletal tumors in which mineralized tissue, blood vessels and giant cells, in varying proportions, replace normal bone. It is an unusual fibro-osseous pathology that develops inside the craniofacial bones, predominantly in the paranasal sinuses. It is common in patients under 14-15 years of age. It's locally aggressive but histopathologicaly benign lesion. Though it mimics active ossifying fibroma, but aggressive in nature. Histological characteristics do not indicate the rate of growth or prognosis, treatment depends on the clinical and biologic behavior of the tumor. We report a case of juvenile ossifying fibroma, in a 13year-old boy. The treatment was radical en-bloc excision and 7years follow-up without recurrence.

KEYWORDS: Psammomatoid juvenile ossifying fibroma; ossifying fibroma; juvenile ossifying fibroma; fibro-osseous lesion; active ossifying fibroma.

INTRODUCTION: Juvenile ossifying fibroma (JOF) is an uncommon fibro-osseous neoplasm which occurs in individuals under 15 years of age. It is also used as a diagnostic tag for a tumor occurring mainly in the paranasal sinuses and identified by fibroblastic stroma containing small ossicles like psammoma bodies. It was first described by Benjamins in 1938 as "osteoid fibroma with atypical calcification". ${ }^{1}$ Later on in 1952, Johnson coined the term "juvenile active ossifying fibroma". ${ }^{1}$ The term itself signifies that it is the tumor of young age and occurs predominantly in children. In reviews published by Slootweg et al. and Hamner et al., the mean age of onset was 11.5 and 11.8 years, respectively, but it does occur in adults. ${ }^{1}$

Histologically, it comprise of a cell-rich fibrous stroma, consist of strands of osteoid cellular without osteoblastic lining, associated with trabeculae of additional characteristic woven bone. Small foci of giant cells may be there. The JOF is non-encapsulated but separated from adjoining bone. It is usually asymptomatic, achieving a large size and exhibiting aggressive behavior, and is often diagnosed as 'juvenile ossifying fibroma', 'aggressive ossifying fibroma' or 'active ossifying fibroma' in the literature. ${ }^{2}$ Because of aggressive behavior and high recurrence rate, incipient diagnosis and total surgical excision are important. Here is reported a case of a massive JOF of the maxilla in a 13-yearold male child.

CASE HISTORY: A 13-year-old male child presented in January 2007 with a painless, progressive swelling of the left face since 7 months. He had no contributory family history or past history. Clinical examination revealed a moderately large left facial mass extending from infraorbital region to upper lip and from ala of nose to zygomatic buttress region. Intraoral examination revealed no apparent mucosal changes with gross expansion of labial cortex and the left maxillary alveolar process extending to the hard palate (Fig. 1A). On palpation, the swelling was hard in consistency with no fluctuation elicited and was slightly tender. The left maxillary teeth were firm. There was no palpable cervical or submandibular lymphadenopathy, and a chest radiograph was also normal. 
Plain X-ray radiographs (PNS, OPG \& IOPA) showed a radiopaque mass in left maxilla, maxillary sinus \& infraorbital region. CT scan revealed a heterogeneous shadow, and a well-defined osteolytic mass involving the left maxilla, maxillary sinus, alveolar bone and nasal cavity. There was destruction of the medial and antero-lateral walls, and the roof of the left maxillary sinus. The eyeball and cranial nerve were not involved (Fig. 2 A and B). Examination of an incisional biopsy specimen confirmed the diagnosis of juvenile ossifying fibroma of the trabecular type. With the patient's and his parent's written consent, we did a radical en bloc excision under general anaesthesia.

The lesion was big, and removed wholly (Fig. 1 B, C and D). On excision, the specimen was characteristically pale-white, rubbery, homogeneous mass with a firm consistency. After achieving hemostasis, antral packing was done and wounds were closed primarily (Fig. 2 C). After the operation, the patient had a good facial appearance and oral function, and no obvious facial deformity (Fig. 1 E). Microscopically, the lesion was not encapsulated and showing no infiltration of surrounding bone. It consisted of cell-rich fibrous tissue containing strand of cellular osteoid without osteoblastic lining, together with thin trabeculae of immature bone containing coarse lacunae with plump osteocytes and lined by a dense rim of enlarged osteoblasts (Fig. 3. A). On the basis of these findings, the lesion was diagnosed as a JOF of the maxilla (a juvenile trabecular ossifying fibroma).

DISCUSSION: Fibro-osseous lesions of craniofacial skeleton are uncommon and are because of substitution of usual bony pattern by fibrous tissues that may mineralize in different forms similar to woven, lamellae bone, or cementum and contain a wide range of separate entities with diverse clinical and microscopic presentation. ${ }^{2}$ The majority of benign fibro-osseous lesions of maxillofacial regions are without any symptoms and are gradually expanding. Further, an abnormal clinical picture with evident rapid and destructive expansion might be seen when the lesion develops in a juvenile patient, particularly under the age of 15 years. ${ }^{2,3,4}$

JOF is an aggressive benign neoplasm mostly present in children and adolescents. It appeared to be originated from differentiation of the mesenchymal cells of the periodontal ligament, multipotential precursor cells, into cementum, osteoid, or fibrous tissue. ${ }^{5}$ Lawton et al contemplated that they possibly arise from the mal development of the tissue generating the bony septa between the roots of molar teeth. ${ }^{6}$ Pimenta et al, reported association of a new tumor suppressor gene (HRPT2) mutation with ossifying fibroma and proposed that these tumors could develop as a result of haplo in sufficiency of the particular gene. ${ }^{7}$

It is difficult to form exact diagnosis criteria for Juvenile ossifying Fibroma. The major features are: a patient below 15 years, the site of the lesion, the radiographic features, and recurrence. According to HAMNER et al. and SLOOTWEG et al., the mean age of onset was 11.5 and 11.8 years old, respectively. 9,10 Clinically, this tumor has overall aggressive behavior than ossifying fibroma. ${ }^{11}$ As was the present case, almost all the cases of Juvenile Ossifying Fibroma are without any symptoms. Usual clinical presentation is a swelling of the maxilla.

When the lesion extends to orbital and paranasal sinuses, the patients may present exophthalmos, bulbar displacement and nasal obstruction. It appears as a discrete mass, well demarcated from the surrounding bone, though not encapsulated.2,4 The radiographic presentations are varied and are usually depend on the lesion's anatomic position and the amount of calcification. Histologically, the lamellae are of different shape, from trabecular to more osteoid. No obvious islands of epithelium or individual epithelial cells are present as seen in odontogenicfibroma. ${ }^{12}$ 
The stroma shows focal areas with stromal cysts and occasional mitoses. Rimming of cortical and reactive bone was seen at the periphery of the lesion. Management and prognosis of JOF is somewhat uncertain. The recurrence rate ranges from $30 \%$ observed by JOHNSON et al. to 58\% reported by MAKEK.13,14 Many authors favor conservative surgery rather than radical en-bloc resection, though recurrence characterized by a high aggressive growth rate. ${ }^{11,15}$ In the present case, as the patient was a child, and the lesion could be distinctly separated from adjacent bone, radical excision of lesion was performed. After 7 years of follow up, there was no recurrence.

\section{REFERENCES:}

1. Brannon RB, Fowler CB. Benign Fibro-Osseous Lesions: A Review of Current Concepts: Advances in Anatomic Pathology, 2000; 8 (3): 126-143.

2. Waldron CA. Fibro-osseous lesions of the jaws. J Oral Maxillofac Surg 1993; 51: 828-35.

3. El-Mofty S. Psammomatoid and trabecular juvenile ossifying fibroma of the craniofacial skeleton: Two distinct clinicopathologic entities. Oral Surg Oral Med Oral Pathol Oral Radiol Endod 2002; 93: 296-304.

4. Williams HK, Mangham C, Speight PM. Juvenile ossifying fibroma: An analysis of eight cases and comparison with other fibro-osseous lesions. J Oral Pathol Med 2000; 29: 13-8.

5. Bertrand B, Eloy PH, Cornelis JP, Gosseye S, Clotuche J, Gilliard CL. Juvenile aggressive cementoossifying fibroma: Case report and review of the literature. Laryngoscope 1993; 103: 1385-90.

6. Lawton MT, Heiserman JE, Coons SW, Ragsdale BD, Spetzler RF. Juvenile active ossifying fibroma: Report of four cases. J Neurosurg 1997; 86: 279-85.

7. Pimenta FJ, Gontijo Silveria LF, Tavares GC, Silva AC, Perdigyo PF, Castro WH, et al. HRPT2 gene alterations in ossifying fibroma of the jaws. Oral Oncol 2006; 42: 735-9.

8. Saiz-Pardo-Pinos AJ, Olmedo-Gaya MV, Prados-Sanchez E, Vallecillo-Capilla M. juvenile ossifying fibroma: a case study. Med Oral Patol Oral Cir Bucal 2004: 9: 454-458.

9. Hamner JE, Gamble JW, Gallegos GJ. Odontogenic fibroma. Report of two cases. Oral Surg Oral Med Oral Pathol 1966: 21: 113-119.

10. Slootweg PJ, Panders AK, Koopmans R, Nikkels PG. Juvenile ossifying fibroma. An analysis of 33 cases with emphasis on histopathological aspects. J Oral Pathol Med 1994: 23: 385-388.

11. Troulis MJ, Williams WB, Kaban LB. Staged protocol for resection, skeletal reconstruction, and oral rehabilitation of children with jaw tumors. J Oral Maxillofac Surg 2004: 62: 335-343.

12. Williams HK, Mangham C, Speight PM. Juvenile ossifying fibroma. An analysis eight cases and a comparison with other fibro-osseous lesions. J Oral Patho Med 2000: 29: 13-18.

13. Johnson LC, Yousefi M, Vinh TN, Heffner DK, Hyams VJ, Hartman KS. Juvenile active ossifying fibroma. Its nature, dynamics and origin. Acta Otolaryngol Suppl 1991: 488: 1-40.

14. Makek MS. So called "fibro-osseous lesions" of tumorous origin. Biology confronts terminology. J Craniomaxillofac Surg 1987: 15: 154-167.

15. Zama M, Gallo S, Santecchia L, Bertozzi E, De Stefano C. Juvenile active ossifying fibroma with massive involvement of the mandible. Plast Reconstr Surg 2004: 113: 970-974. 


\section{CASE REPORT}

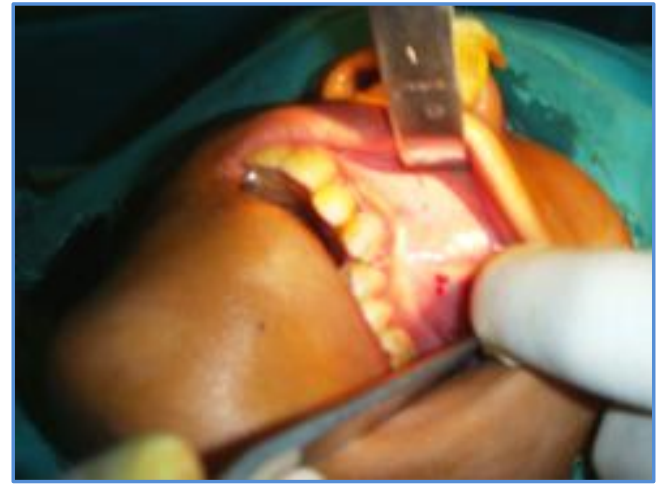

Fig. 1(A): Gross expansion of the left maxillary alveolar process

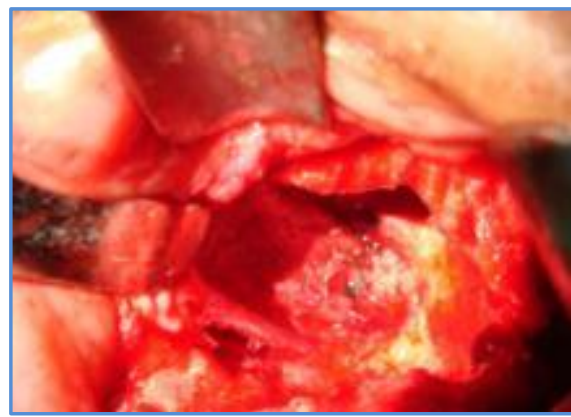

Fig. 1(C): Defect after removal of tumour

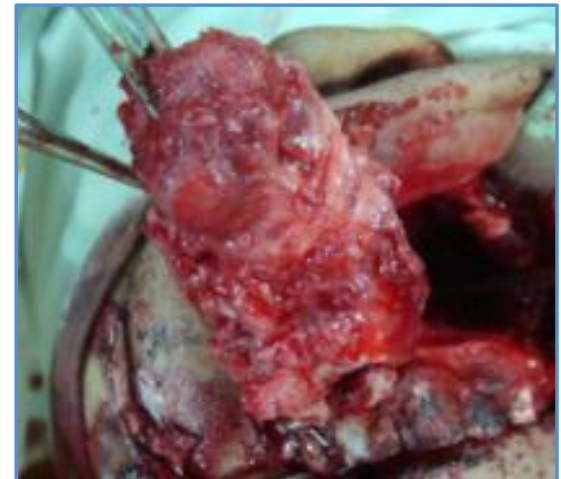

Fig. 1(B): The tumour was removed wholly

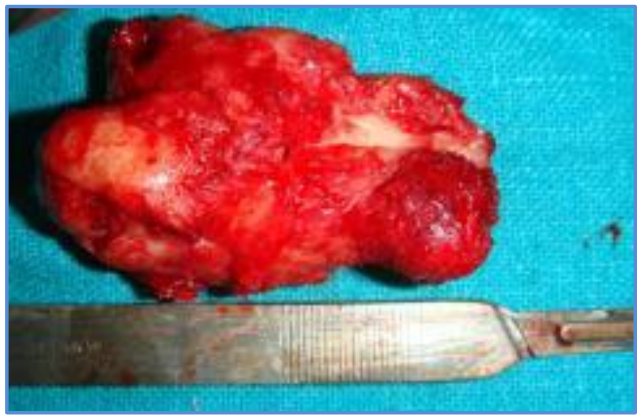

Fig. 1(D): Tumour mass

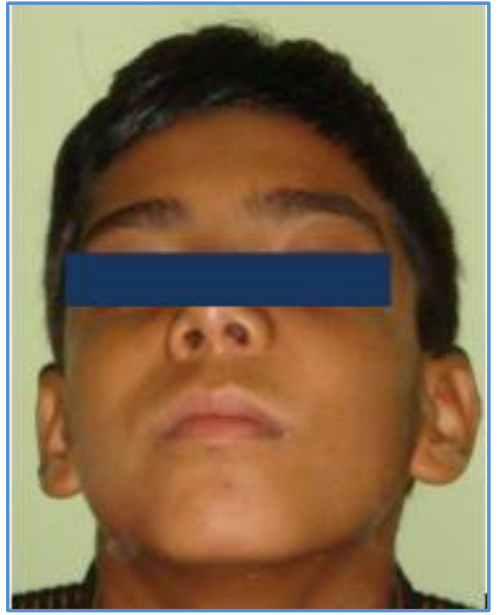

Fig. 1(E): Postoperative facial appearance 


\section{CASE REPORT}

Fig. 2 (A and B): Computed tomography (CT) of the skull showing a mixture of heterogeneous shadow, and a well-defined osteolytic mass involving the maxilla, maxillary sinus, alveolar bone and nasal cavity.

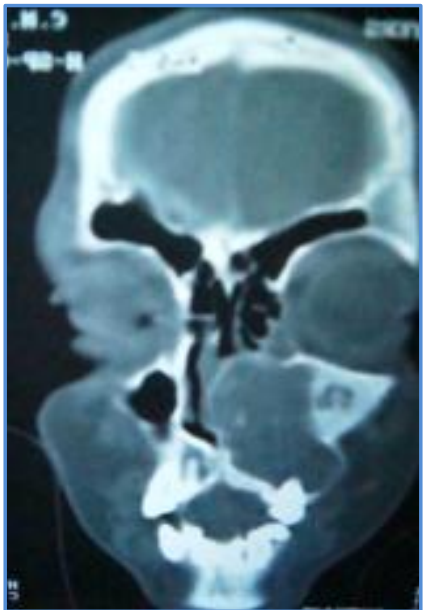

Fig. 2 A

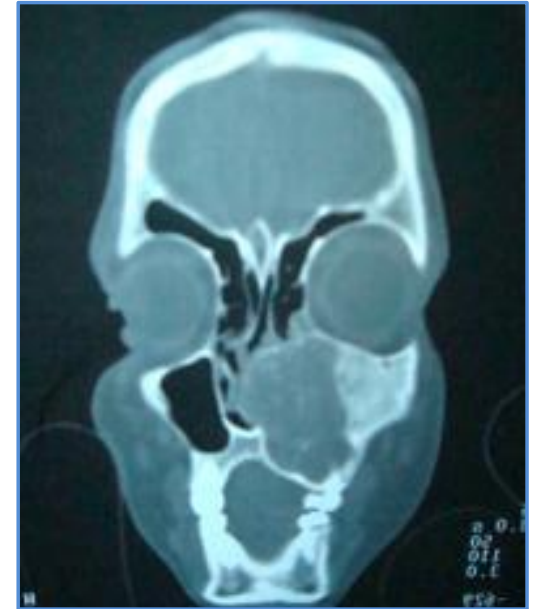

Fig. 2 B

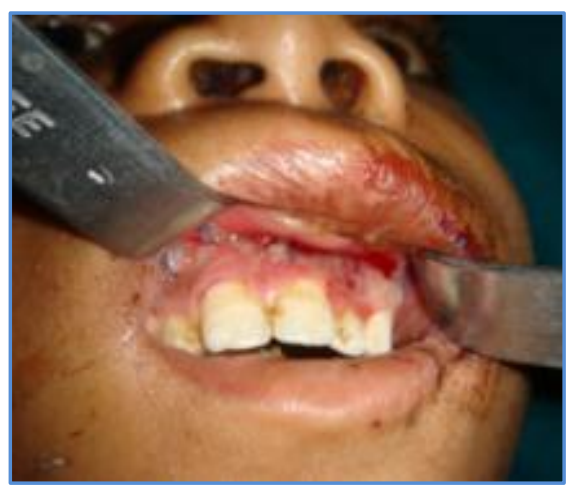

Fig. 2(C): Primary closure of defect

Fig. 3(A): Immature bone trabeculae are lined by a dense rim of enlarged osteoblasts Mitotic figures are visible in the stroma, Cellular osteoid without osteoblastic rimming.

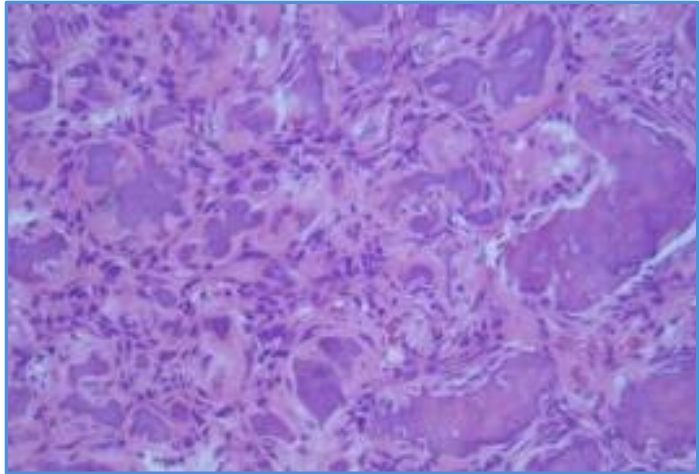

Fig. 3A 


\section{AUTHORS:}

1. Ranjit S. Mandwe

2. Swapna Puri

3. Vivek Kolhe

4. Shrikant Shingne

\section{PARTICULARS OF CONTRIBUTORS:}

1. Assistant Professor, Department of Oral \& Maxillofacial Surgery, V.Y.W.S. Dental College, Amravati.

2. Post Graduate Student, Department of Orthodontics, Dabasaheb Kalmegh Dental College, Nagpur.

3. Lecturer, Department of Oral \& Maxillofacial Surgery, V.Y.W.S. Dental College, Amravati.
4. Lecturer, Department of Conservative, V.YW.S. Dental College, Amravati.

\section{NAME ADDRESS EMAIL ID OF THE} CORRESPONDING AUTHOR:

Dr. Ranjit S. Mandwe, \# 34, Santaji Nagar,

Amravati,

Maharashtra.

Email: ranjitmandwe@yahoo.com

Date of Submission: 17/09/2014.

Date of Peer Review: 18/09/2014.

Date of Acceptance: 14/10/2014.

Date of Publishing: 20/10/2014. 